\title{
OFFICE BUILDING LOCATION RELATED TO GREENERY TYPE CASE STUDY OF THE MAIN BUSINESS DISTRICTS IN PARIS
}

\author{
Irina Mohora \\ $\mathrm{PhD}$, "Politehnica" University, Faculty of Architecture and Urbanism,Timisoara, ROMANIA, \\ irina.mohora@student.upt.ro
}

\begin{abstract}
Emerging built landscapes and urban densities, together with a distressing human-nature estrangement, represent the main challenges of today's developers. Real concerns such as pollution, climate change or nature-deficit-syndromes impact the human world on every scale, raising attention towards seeking change in attitude and low impact methodologies in the built context. Beginning with the Industrial Revolution when new technologies encouraged architectural reinvention, continuing through the Digital Era that transformed building and thinking once again, the natural environment has undergone a constant decrease in surface and importance in cities worldwide.
\end{abstract}

Corporate architecture has always adopted building innovation, aiming for higher prestige and marketability through a polished, impressive, even intimidating image. Exterior aspect, energy performance, indoor quality and technology-proneness are some of the points pursued by both managers and investor when choosing a new business site. But the foremost aspects when buying or renting a new office building are location and price.

Increasing demands for office surface have led to vertical building, which rose new issues in the European urban network, due to strict urban requirements. Thus, the selection of optimal office building location has been a challenge for the narrow-street structure of European cities, leading to several typologies: historical districts, urban and suburban areas or independent workplace centers. Each location has in turn determined different intervention types: refurbishment or renovation, functional conversion, new building, causing various dialogues with the urban nature.

As every European city and country has its own regulations depending on geographical, climatic, cultural and political factors, the research was focused on one case study that allowed drawing relevant conclusions on the matter. With its rich urban and architectural background, a diverse and ever developing business environment, the French capital, Paris, is among the most interesting European metropolis for its urban development. A clear distinction can be made here between three different typologies of commercial districts: historical type (the Central Business District, in western Paris), the modernist La Défense (on the Northern-Western outskirts), the newer Saint-Denis/Saint-Ouen and Issy-les-Moulineaux (in the Northern and Southern suburbs). Approximately 100 buildings from these locations and the close vicinity have been analyzed aiming to classify their connection to outdoor and indoor plants and observe how these reflect on real estate rent cost. Another argument for choosing Paris for this case study is the relative recent implementation of the "Biotope Area Factor" principle that demands a balanced use of vegetation in the built fabric for both new constructions and refurbishment projects. Alike other several European capitals (Berlin, Stockholm, London) the urban landscape is slowly transforming towards a more sustainable one, while keeping a certain flexibility in selecting the green systems.

The main objective of this research is to determine the office building-greenery relation from economical, urban and architectural points of view. It is essentially important to understand how energetic certificates and 
green space proximity rise the real estate value, making the building more attractive, updated and innovative regarding ecological visions. Furthermore, establishing link typologies between location, building type and vegetation can highlight the optimal greening potential of each site type. A construction located in the dense city center is expected to benefit from more introverted nature (interior courtyards, green walls, etc.) comparing to a less dense suburban site.

Although the study was conducted on a small sample relative to the complexity of the topic, the model might be further applied on a larger scale, comparing different cities worldwide, practically creating local frameworks for architects, managers and investors, towards responsible implementation of vegetated material in the office building sector.

Keywords: office location, European green space regulation, biotope area factor, real estate value

\section{INTRODUCTION}

\subsection{Contemporary Workplace Challenges}

Building-nature connection is mandatory for the modern urban context, with various implications in the proper functionality of society. Factors like environmental pollution, stressful working conditions, along with an ascending built density, have led to a constant estrangement of nature from the city and consequently, of man from nature, abolishing a strong connection carried for thousands of years along with the evolution of humanity. Health and wellbeing rely on this intrinsic affiliation to nature (Kellert and Wilson, 1993), proof being given by illnesses due to prolonged indoor activities, lack of exercise, low quality of built fabric.

Office design history shows that formerly, natural light, window views and access to greenery were specifically reserved features for the hierarchical leaders. Increased comfort, improved materials and furniture, along with a generous office surface, displayed the importance of the person inhabiting the space. Nowadays, hierarchy tends to fade, as newer collaboration patterns emerge, simultaneously highlighting the major role of each employee; consequently, access to basic comfort features is obligatory and is being complemented by functional and psychological characteristics of space (Vischer, 2008), that participate in occupant wellbeing, creativity and productivity.

Outdoor nature makes subtle buffers between public space and the office setting, having great potential in creating social bonds. A sustainable approach is necessary in order to soften visual and physical limits imposed by the monumental aspect of modernist corporate buildings. While urban regulations dictate distances to green space, minimal vegetated surfaces and the quality of planted material, dependent on geoclimatic regions, updated certification standards aim to introduce frameworks to implement coherent strategies, ensuring a uniform approach while keeping the necessary flexibility.

In pursuance of obtaining viable conclusions based on the present research, the study had to be narrowed down to a specific location. Therefore, based on the professional design experience unfolded in the French architectural background, the dynamic development and ever-changing business context, the city of Paris represented a strong basis. The sustainable visions of the Parisian municipality, backed by a solid urban strategy of extensive green development, aim to limit the general carbon footprint by providing new vegetated spaces with the aid of urban guidelines, energetic certificates, the involvement of citizens, public and private sector. This holistic vision targeted towards a sustainable scope and the wellbeing of citizens, is an example of good practice, reflected to a certain extent in the business sector.

\subsection{Office Building Insertion in the European Urban Context}

Construction innovation trends are immediately reflected in office buildings whether it implies new materials (glass, steel, standardization), technologies (the elevator, curtain walls) or general constructive typologies (sky-scrappers). Albeit the rapid adaptation of the field to innovation, urban planning was not as agile and flexible to receive the new architectural objects that drastically changed the cities' skylines. Respecting the memory of place and heritage, the European context confronts specific constraints due to strict urban regulations for dense historical areas, originated in the Medieval Era (Saval, 2014, chap. 4), that describe the most extensive urban agglomerations. Building heights were generally limited to five or six levels in historical centers, thus decentralizing all tall construction projects outside the city limits, leading to the emblematic business district satellites and an organic model of urban growth. Choosing the ideal site for an office 
building has always been an architectural, urban and real estate challenge, determining multiple insertion patterns: historical centers, metropolitan, suburban, isolated buildings. In turn, each site influences certain intervention projects adapted to context and local requirements: restoration, refurbishment, functional reconversion, new building in historical or modern context.

Consequently, various location categories have emerged, specific to the European continent, with distinguishable features, accessibility requirements, unique urban guidelines and constraints. Each typology engages differently to urban nature and interior ecological systems, depending on several factors that will be analyzed in detail in the following sections.

As height limitations deterred vertical expansion, a growing need of workplace surface determined urban density growth, occurring in lowered planted surfaces inside the city borders, specifically closer to the already dense historical districts. This involution of greenery firstly and locally impacts human physical and psychological condition and in a broader view, worsens air pollution, natural calamities, reduces local fauna and flora, having irreversible negative effects on the Biosphere. This research aims to analyze and link the two worlds, the office and inner-city nature, for a holistic approach in the near future.

\subsubsection{Urban Development and Green Space Relatedness}

Whether we speak about new constructions, relocation, expansion or refurbishment, there are several arguments to consider when discussing the complex subject of workplace location choice, as it foremost implies economic factors as rent, energy consumption, spatial status and quality, necessary investments. Creation and maintenance of vegetated systems is not a priority in investors' expenses, while energetic efficiency lately became an important issue reflected in international certificates. As a result, there is a stringent need to establish better guidelines for green space implementation for this to be taken into account. Paradoxically, real estate industries rely on built environment expansion, which implies a constant reduction of horizontal planted surfaces inside the city boundary and the vicinity. Nevertheless, rent and selling prices also depend on visual and physical access to green space as part of a general sustainable vision, whose visibility is of great importance to corporate clients. A balance is needed in order to answer the challenge of real estate development in harmony with nature.

One must not overlook that an optimal architecture - nature liaison might bring numerous benefits, beyond aesthetically pleasing, enhancing quality of life, physical and psychological recovery (Kaplan, 1995), all relying on the intrinsic human-nature affinity defined by the American biologist Edward Owen Wilson as Biophilia (Wilson, 1984). On this regard, natural landscapes close to build areas are instinctively appreciated, but on the other hand, a wider built surface brings higher profit; so, it is interesting to analyze how greenery could be actually taken into account for it to be both economically and psychologically profitable. Nature's influence on wellbeing is a less quantifiable asset than economical gain, but the direct positive effect on productivity and creativity, the most important "tools" of contemporary work, are relevant enough for this to be even included as a management strategy.

\subsubsection{European Landscape Regulation - The Biotope Area Factor}

Each European city has its own Masterplan showing a framework for future developments. In recent years, green Masterplans emerged due to a raising need for sustainable approaches towards the green, blue and built networks. Cities can no longer be associated exclusively with buildings and grey infrastructure, but as a whole system of interconnected networks, functioning as a properly connected organism, to the large scale of the Global Biosphere. Office buildings, in turn, must obey these laws and make integral part of a holistic way of thinking and acting.

As stated previously, an office site implies a series of interventions on existing structures or entirely new constructions. Whatever the solution, architects must take note of local context regarding green space. (Kazmierczak, A. and Carter, 2010; Territoires, 2015). According to the Biotope Area Factor, any new or refurbished building must satisfy imposed ecological rules in order to receive building permission. The law demands for a balance between planted surface, the quality of green systems and planting support, all correlated with the resulting built surface. Several Western European capitals have already established clear obligations regarding proportional built-planted development under the definition of Ecological coefficient or "Biotope Area Factor". The regulation imposes the implementation of vegetated systems even in densely built zones, simultaneously permitting flexibility of choice between various greenery types if the planted percentage is met for the specific plot. Targeting towards evenly distributed non-built areas in the city, the green infrastructure is allowed to flourish and work fluently with the grey infrastructure, while keeping intense densities under control. 
Valuable green surface expansion is among the Parisian municipalities' targets in the near future, for, due to an intense densification of the central area, vegetation was mostly eliminated or still remains in very few concentrated zones such as parks or interior courtyards. As Figure 1 shows, there is noticeable vegetation difference between the central and marginal districts, relative to built densities (Atelier Paris d'urbanisme, 2004; Locaux, 2018).

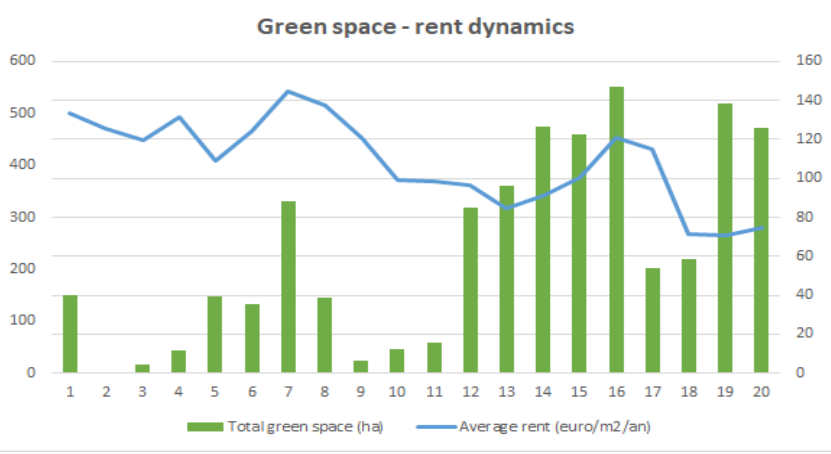

Fig. 1 a) Green space - rent dynamics in the 20 Parisian districts

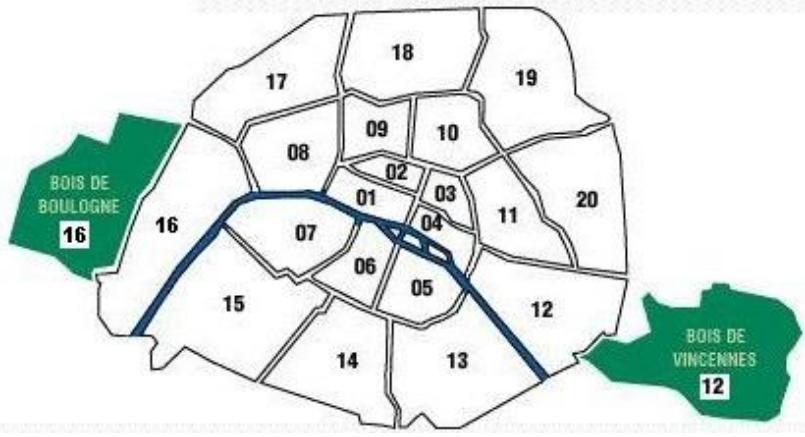

b) District cartographic identification

In this regard, various vegetation-wise strategies have emerged for investors, public and private sector. For instance, Parisian citizens can participate in the greening of their neighborhoods by obtaining a "Vegetalization permit" (Paris Municipality, 2017) which authorizes small local interventions on public spaces, to enhance the greening potential of streets and public squares.

\section{GREENERY AND REAL ESTATE VALUE}

Window view orientation is known to be among the determinants of hotel room prices. The presence of rich natural landscapes such as seaside views, mountainside, lakes, forests, parks, influences room rates substantially, depending on location, hotel standards and other variable factors. Secondly, residential prices and rates of attractiveness are also influenced by the presence of urban greenery, although a high rate of subjectivity is involved in this process (Szczepańska, Krzywnicka and Lemański, 2016). Generally, people are inclined to pursue and pay more for proximity to nature when it comes to personal choices (hotel rooms for leisure time, homes).

What about greenery connected to office buildings? The decision process for office building sites has always been a management strategy undertook by private investors and company leaders who primarily took economic factors into account. From a pragmatic point of view, greenery involves additional costs regarding maintenance, specialized personnel for project and implementation, irrigation, etc., so throughout history it never constituted a priority, nor an apparent necessity for an additional planted area to be reserved next to an office building that already required significant costs. As it is difficult to estimate positive impact of indoor air quality on the health and wellbeing of occupants, it is equally disputable on how outdoor greenery can impact the same aspects of utmost importance for companies in order to become profitable enough to consider incipiently in real estate search and architectural design.

\subsection{Sustainability Relevance in Corporate Culture}

There are several possible paths that have already emerged in scientific management, for greenery to be understood as a necessity in corporate real estate and exploited for its true value. To begin with, present day corporate strategies deeply rely on coherent company cultures, innovation and visibility to communicate a clear message to clients and potential future employees. Regardless of the field, productivity, industry, finance, exploitation or information technology, etc. (Eichholtz, Kok and Quigley, 2009), one can easily notice a common direction, influenced by internal beliefs or externally dictated trends: sustainability.

A sustainable vision is seen as future-oriented with respect for future generations, nature and life in general and can be translated into multiple scenarios. Whether we think of using regenerative resources and technologies, green systems (solar panels, heat pumps, aeolian power, etc.), recycling methods, green walls, terraces and parks or any other ecological scheme, these will be perceived as steps towards environment improvement. Certificates and building quality evaluation methods (e.g. Level(s), BREEAM, LEED, WELL, SITES), are sets of building features showing inclination towards wellbeing and ecology, that demand the achievement of certain quality standards through some of the recalled systems and other spatial features. In addition, recent urban regulations and general masterplans in the European Union, have introduced strict conditions to preserve planted surfaces or provide valuable greenery within each project, 
relevant to plot size. This enforces both investors and design professionals to align their projects to uniform regulations, participating in environmental improvement.

On the other hand, contemporary work strategies lead to an active involvement of employees in the decisional process, as they are encouraged to express their desires regarding spatial configuration, amenities and comfort aspects. This is a management strategy that attracts and helps retain staff for longer periods of time, as the involvement in their surrounding space is crucial from psychological points of view. Natural light, indoor and outdoor leisure spaces, indoor plants to enliven atmosphere, local temperature and ventilation adjustments, are among the most requested elements for employee comfort in a workplace.

It is important to note that certain companies will consider paying an extra amount to fulfill these conditions and express their ecological orientations, while other companies will not find this a priority (Eichholtz, Kok and Quigley, 2009).

\subsection{Economic Advantages of Green Buildings}

As discussed previously, there are several conveniences when choosing a green building: lower operational and maintenance costs (30\% less energy consumption), occupant wellbeing that leads to raise in productivity and efficiency, less absenteeism and reduced medical leave. Consequently, the company is renowned for promoting environmentally-friendly attitudes, fostering sustainable ways of working and living. Another major advantage is the anticipation of imminent urban regulation transitions regarding green spaces and architectural interventions on existing and new buildings. Thus, following a correct ecological framework beforehand, grants substantial renovation and conformation costs that could soon apply on a wider scale (Miller, Spivey and Florance, 2008). This mindset is currently adopted quickly by non-profit organizations, startups and specialized ecologically-oriented companies. Instead of being an isolated approach, sustainability should become norm in order to have a significant impact.

\subsubsection{Financial Theory Overview}

For the theoretical substantiation of the research, basic financial knowledge had to be taken into consideration for a better understanding and correlation of green space as a real estate criterion to the building, its terrain and the location in the city. Two valuation methods are to be taken into consideration: the empirical method and financial theory method (Thion, 1993).

The first procedure, a rather traditional way of evaluation, involves observation and market comparison, relying on the identification of similar estates and looking at comparable characteristics as: location, physical features, uniqueness and property condition in time. Local average market price is very important in this analysis as it represents a reference point and it highly influences prices of the surroundings. The second strategy implies an estimation of the property dynamics in the future, its selling potential, based on both present features and its history. The income approach is calculated as the ratio between annual revenue and property value and it is a divisor that allows a revenue to be transformed into value. In other words, the capitalization rate is inversely related to building class; the more valuable the building, the lower the capitalization rate (IROVAL, 2012). Thus, features such as interior courtyards or important land surfaces determine extensively lower rates than similar buildings without generous land.

\subsubsection{Property Valuation Criteria}

According to financial theory (Clermont, 2018), the main valuation factors of rented and sold office spaces are: geographical features (location and accessibility), building features (number of levels, planimetry, spatial organization options, capacity, complimentary amenities), energetic performance aspects (existing and expected certifications, materials and resources usage, green technologies), interior comfort aspects (leisure amenities, greenery, natural light, ventilation and temperature).

In the light of these general guidelines, an analytical study has been undertaken on a sample of approximately 100 office buildings and sites with integral or partial office function from the French context, Paris, to determine preliminary discussions and conclusions related to green space in the proximity and interior of workspaces and whether it shows a potential influence over real estate value. In regard to the stated arguments concerning financial valuation of real estate, rent price, obtained through both comparative and capitalization methods (Thion, 1993) is taken into consideration as an identification instrument and measuring unit for the physical characteristics of the site.

\section{HYPOTHESIS}

Green components in contemporary or refurbished buildings enhance property value: buildings are healthier for the environment inside and out, better for occupants, more attractive, a sign of distinctive character in a 
modern, uniform context. These constructions represent the embodiment of uniqueness and innovation related to location and adapted to contemporary work and the digital Era. Variations will certainly emerge depending on position within the built tissue, regarding distinct traits of each studied district. For instance, the CBD (Central Business District) and La Défense are the most expensive (Locaux, 2018) for completely opposite arguments: the CBD depicts the most distinguished historical office character, core of the Parisian tertiary activity, while La Défense is renowned for its innovation-oriented strategy, skyscraper skyline, so uncommon for an old structured European capital. It is of equal importance to note differences of price between green, refurbished, unclassified buildings of the same neighborhood.

The reasoning behind great differences between closely located buildings is partly due to the recent urban regulation, applied in several European cities. Comprised in the Parisian local urbanism plan (Atelier Paris d'urbanisme, 2004), the Biotope Area Factor, aims for any building project, new or refurbished, to comply with minimal surfaces of quality green substrate and planted material. The actual result is that updated or new buildings become more attractive on the real estate market due to building conditions, modern facilities and functional combination, representing fewer initial investments and maintenance costs for future corporate clients.

Regarding the previous statements, this research aspires to answer the following question: Do green space proximity or interior green systems influence renting price, thus property value? A second presumption is that remoteness to urban green space is balanced by higher indoor green systems and vegetated surfaces within the building.

\section{METHODOLOGY}

The paper will focus on the identification of sustainable characteristics, building - green space relatedness, referring to architectural and economical aspects. Property value and renting price are being established taking into consideration a wide range of criteria and financial methods as stated in the previous section, but special focus will be given to natural elements and affiliation.

Firstly, building location in Paris, as in any other metropolis of this caliber, highly influences real estate price, relying on proximity to remarkable landmarks, accessibility to transportation cores and closeness to the urban center and main business districts. Consequently, the selection of buildings was made taking into account the four principal quarters, with the CBD Western Parisian quarter being the most expensive, followed by La Défense and finally Saint-Denis/Saint-Ouen and Issy-les-Moulineaux.

The comparison of several location typologies situated in close vicinity, brings the emphasis on unique building features such as: nearby parks, forecourts, interior courtyards, vegetated terraces, green walls and other less visible characteristics, found in various local sources: sustainability certifications, functional characteristics, planimetry. It is equally relevant for the study to compare districts and buildings within the same area for a wider view over the subject. A first phase or filter was the classification by location, simultaneously looking at: position within city boundaries, built tissue density, urban typology, functional context. Secondly, a set of general information on each site was sought after: price, accessibility or nearby means of transportation, construction/renovation year, functional characterization, planimetry, position relative to neighboring buildings. Thirdly, visible and non-visible sustainable characteristics were investigated, both empirically and descriptively: certification typology/non-certified, distance to urban green spaces, green facilities within building, landscape window views, urban or natural predominant landscape.

A sample of over 100 office sites was chosen from diverse city districts. It is of equal importance to include both buildings that fulfill as much as the above criteria and several that are not yet updated to green norms. Constructive character varies from historical sites, new constructions, refurbishments, modernist structures, small or large; as prices are indicated in euro/ $\mathrm{m} 2$ / year, site dimension does not impede the analysis.

\section{CASE STUDY}

\subsection{Characterization of the Main Parisian Business Districts}

With a continuous development initiated in the 1800s (emerged in the Western part of Paris) (Urbaine and Po, 2015), facing multiple urban restrictions and simultaneous investment opportunities directed towards newly built and existing urban areas, the Parisian business landscape is among the most rich and diverse on a worldwide scale. The four main tertiary districts are constantly being developed, modernized and updated to the latest ecological regulations, considering both interior space quality and overall ecological impact of the building, in order to remain attractive in an extremely competitive real estate market (Urbaine and Po, 2015). 
Uniqueness and diversity distinguish Paris from other metropolis, as a wide offer includes all project scales, building typologies, site locations and prices, for every company size. The oldest, most prestigious historical business quarter, the CBD (Central Business District-founded in 1800) is in the heart of the French capital and overlaps with the first, second, eighth, ninth, sixteenth and seventeenth arrondissements (Parisian districts). Prices in this district range around an average of 500 euro and the tenants include the most distinguished local and foreign companies (law, finances, consultancy, fashion, real estate, etc.).

The second and worldwide famous quarter, La Défense, was built starting from the 1960s, it is located in the prolongation of the Champs Élysées axis and is a contemporary reflection of the Triumph Arch on the one hand, being a modern counterpart for the $\mathrm{CBD}$, a modernist workplace complex on the other hand. As the first location to host skyscrapers that were not allowed inside the city boundaries, La Défense has radically changed the Parisian skyline.

Newly developed on former recovered industrial sites, the Saint-Denis/Saint-Ouen (Northern suburbs) and Boulogne Issy-les-Moulineaux (South-Western suburbs) districts, concentrate the majority of information and media services, complementing the more traditional character of the other two zones (Urbaine and Po, 2015). Emerging on existing suburban areas, the two districts are undergoing massive sustainable strategies, being highly innovative in this sector. Although each described region presents distinctive urban features, different historical origins and determine multiple building typologies, the entire built tissue is subject to the same ecological regulations concerning green space relatedness and interior quality norms. The four business districts represent different relationships to the natural environment, thus, for the scope of this study, the selected buildings will be classified into three areas as following: central (the CBD and the close vicinity), urban (all the other central arrondissements) and suburban (La Défense, Saint Denis, Issyles-Moulineaux and other isolated quarters of the Parisian outskirts).

Each site is described individually using the above-mentioned criteria, emphasizing ecological features through a sum of information generically defined as "green index". The greenery attributes marked with ten points if present within the studied building are: sustainable certificates (refurbished-historical site, refurbished-modernist, new certified, modernist (50s-90s) or uncertified), exterior green spaces (park, urban trees, courtyard, river banks), interior green systems (accessible terrace, green terrace, atrium, green wall, courtyard). This criteria selection has allowed a general overview and a better comparison to rent prices and distances to urban greenery.

\subsection{Results and Discussions}

\subsubsection{Site Classification and Green Criteria Overview}

Location within built context is the leading criteria, used to classify the selected buildings. Hence, Figure 2a) shows that $40 \%$ of the chosen sites are located in the historical area, accurately overlapping with the Central Business District, whereas urban central sites are located in close vicinity or in the same districts as the historical sites but do not present historical features. On the other hand, urban peripheral sites are situated in the margins of central Paris in less attractive districts regarding office space. Lastly, Suburban locations stretch outside the city outskirts but are well connected to the metropolitan network.

Although $36 \%$ of the analyzed buildings are not certified (Figure $2 b$ ), the vast majority has earned an interior quality or energetic certification either undergoing a retrofitting process or by satisfying the necessary features within a new building project.

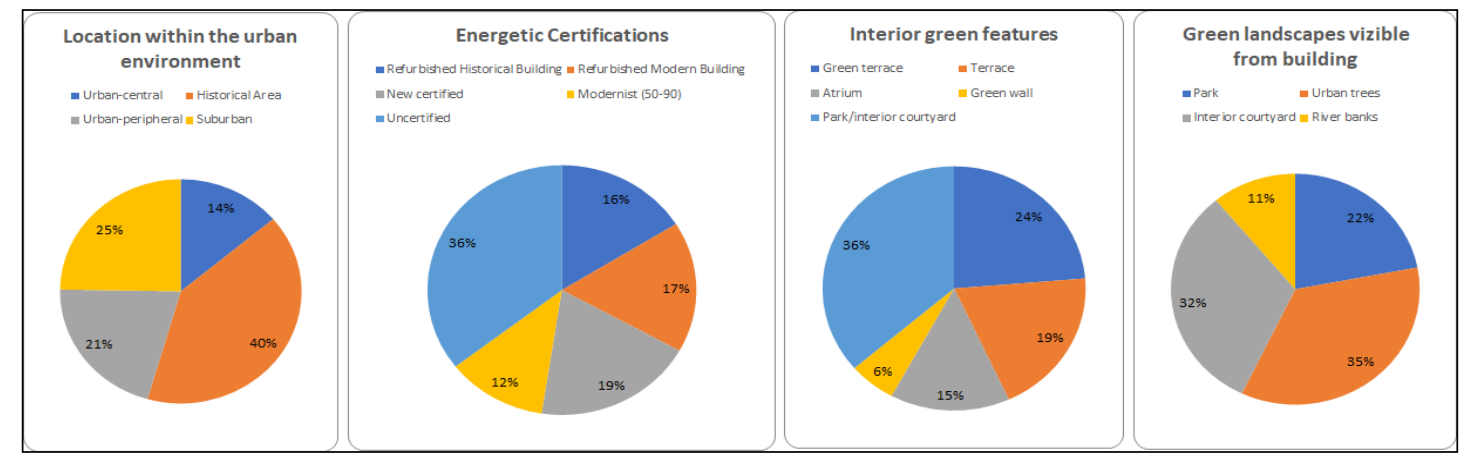

Fig. 2 a) b) c) d) Site classification and sustainable criteria overview

As an essentially old structured city, interior courtyards are typical for historical context development, so it is not surprisingly that the typical interior green system is the patio $(36 \%$-Figure $2 \mathrm{c})$. It is encouraging to notice 
that green terraces are next to be implemented, but green walls are the least used for, these systems are not yet widely feasible due to high maintenance costs. In addition, typical natural window views (Figure 2d) are oriented towards interior courtyards (32\%) topped by urban alignment trees $(35 \%)$, mostly found in wider street networks and lesser in dense historical contexts.

\subsubsection{Greenery ratio within selected Parisian office buildings}

The following comparative charts aim to highlight and define associations between urban green space accessibility, appreciated by distance in meters, introverted greenery, valued through the green index and finally the reflection in yearly rent price per square meter, regarding the three identified location typologies.

Consequently, Figure 3 shows a first descriptive analysis that emphasizes occasional closeness to urban green spaces and an average green index of 400 for historical districts. Observing the highest index (900), one can notice that the site also has the highest rent price (840 euro/m2/year), followed by other two sites with indexes of 800 and 700 demanding prices of 720 euro respectively 810 euro. As a rule, all high index locations also have the highest rents and facilitate easy access to urban greenery.

In this case, prices are highly influenced by landmarks and building prestige, as a result, significantly elevated prices are found in both low and medium indexed locations. On the other hand, remoteness to exterior greenery does not seem to be compensated proportionally by building-related greenery or other systems.

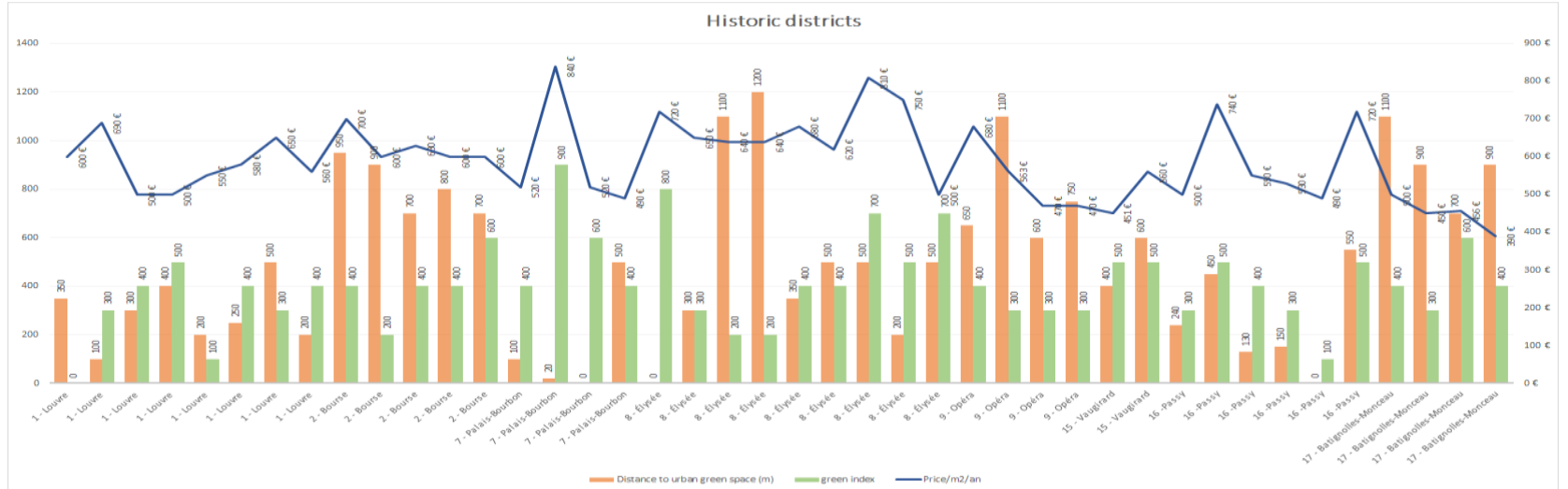

Fig. 3 Historic districts analysis

Concerning other urban districts analyzed in Figure 4, architectural landmarks do not represent a criterion for price variation and green indexes tend to rise in value. As a first observation, the highest green index (900) corresponds to one of the highest rent prices (540 euro), the rule applies also to the following two index rates (800). It is to be noted that the general green index is higher in this region, an average of 500 , but prices tend to drop drastically independent of greenery relationship, as the sites are located further from the center.

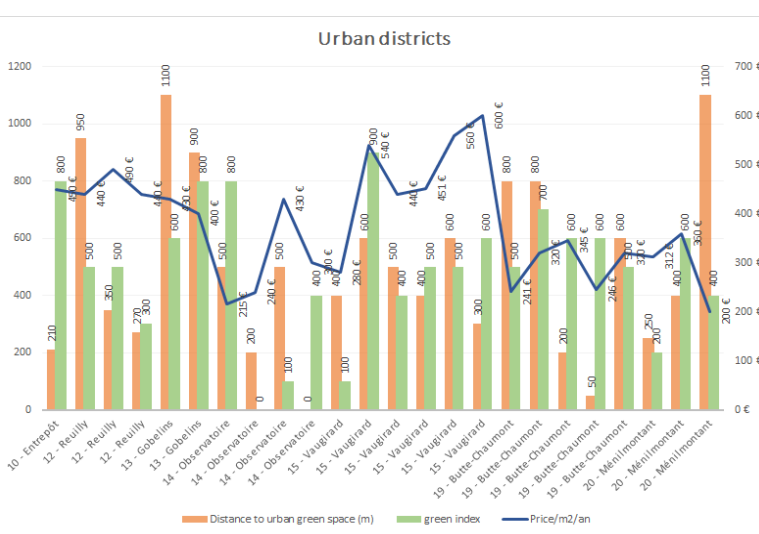

Fig. 4 Urban district sites analysis

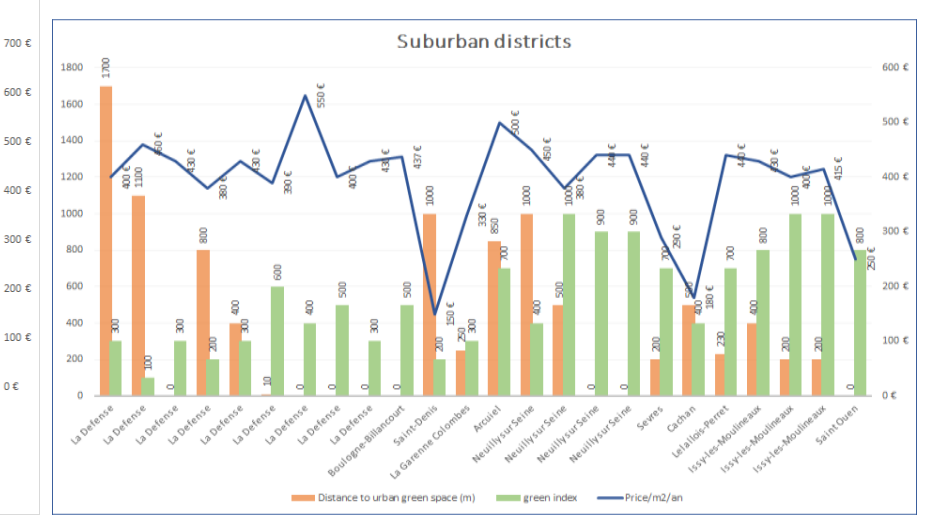

Fig. 5 Suburban district sites analysis

Suburban districts (Figure 5) show a different dynamic comparing to the previous situations, as suburban locations secluded from the main central area, show a major drop in price and lower index. On the other hand, the famous La Défense district presents high prices independent of obviously lower green indexes, 
occasionally compensated by closeness to urban nature. It is also indisputable that Issy-les-Moulineaux and Neuilly sur Seine are the greenest with both high indexes and nearby greenery. These have an evident influence on price range, as they reach those of La Défense, by offering a different type of suburban environment.

\section{CONCLUSIONS}

Office site location choice is a complex process that rises multiple challenges and stakes. In a dynamic environment like Paris, the office building is a massive investment that might enhance or break down a business. Factors as accessibility, district character, building prestige and condition are mostly sought after when launching a site search, rent price being an effect of the mentioned factors.

Concerning indoor and outdoor greenery, the research showed a clear influence over price in situations with both high green index and closeness to nature. A well-functioning ensemble is constituted of sustainable characteristics as: energetic certifications, green systems within the building, outdoor natural areas, sustainable materials, simultaneously aiming to reduce energy consumption, lower gas emissions, provide a healthy interior environment and relate to outdoor greenery.

Average and low sustainable factors represent isolated and possibly disparate green attributes that do not work together with the building and the urban environment. As a result, these sites mostly adopt local prices as they do not offer improved interior conditions or energy efficiency characteristics.

A graphical conclusion is expressed in Figure 6 where all the analyzed districts are ordered according to the resulting green index. Observing the extremes, one must realize that historical sites, such as the Louvre district, La Défense or Élysées have the highest rents despite of lower green indexes due to high built densities, while on the contrary, lower density sites as Issy-les-Moulineaux or Neuilly-sur-Seine show greater connection to natural surroundings, also having easier access to outdoor greenery. Although the index dynamic is obvious, prices tend to keep an average of 400 euro with isolated extremes of 200 or 800 , a result of the previously explained inconsistency of green systems implementation.

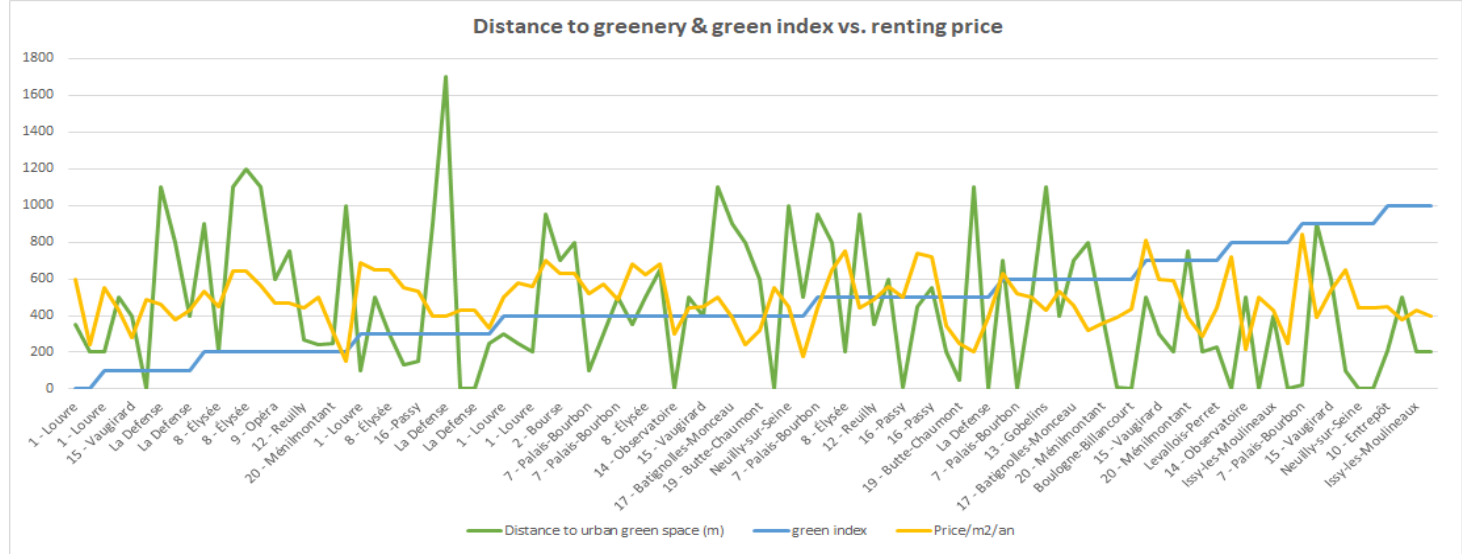

Fig. 6 Distance to greenery and green index relative to rent price

The present research is designed to define the status and importance of green features in the decisional process of office building selection. Aimed equally towards investors and field professionals such as architects, urban planners and consultants, the study serves as a base to further develop a framework of criteria regarding greenery importance from an environmental and economical point of view. Although Paris was subject of the actual study, the method can be extrapolated to any geographical region where new location typologies and natural relationships might emerge. The approach can bring awareness regarding greenery-business sector relatedness and highlight numerous benefits to contemporary urban landscapes and the people who live and work within.

\section{REFERENCE LIST}

Atelier Paris d’urbanisme (2004) Developper le vegetal a Paris: Les nouvelles regles du Plan local 
d'urbanisme de Paris.

Clermont, T. (2018) L'évaluation de l'entreprise individuelle - les locaux professionnels, L'évaluation de l'entreprise. Available at: https://www.compta-facile.com/evaluation-locaux-professionnels-entrepriseindividuelle/ (Accessed: 2 September 2018).

Eichholtz, P., Kok, N. and Quigley, J. M. (2009) 'Why Companies Rent Green: CSR and The Role of Real Estate', The Academy of Management Proceedings, 2009(1), pp. 1-6. doi: 10.5465/AMBPP.2009.44248224.

IROVAL (2012) 'Bazele evaluării', Uniunea Nationala a Evaluatorilor Autorizati din Romania.

Kaplan, S. (1995) 'The Restorative Benefits of Nature', Journal of environmental psychology, pp. 169-182.

Kazmierczak, A. and Carter, J. (2010) Berlin: The Biotope Area Factor.

Kellert, S. R. and Wilson, E. O. (1993) The Biophilia hypothesis. Island Press. Available at: https://books.google.ro/books/about/The_Biophilia_Hypothesis.html?id=oMzqiX3lH-UC\&redir_esc=y (Accessed: 7 June 2017).

Locaux, B. (2018) Prix affichés des bureaux Paris. Available at: https://www.bureauxlocaux.com/prixmarche/bureaux/paris (Accessed: 10 August 2018).

Miller, N., Spivey, J. and Florance, A. (2008) Does Green Pay Off? Available at: http://www.greenbiz.com/news/reviews_third.cfm?NewsID=35955.

Paris Municipality (2017) Végétalisons la ville - Paris.fr. Available at: https://www.paris.fr/vegetalisonslaville (Accessed: 30 October 2017).

Saval, N. (2014) Cubed: A Secret History of the Workplace. Available at: https://www.amazon.com/CubedHistory-Workplace-Nikil-Saval/dp/0385536577.

Szczepańska, A., Krzywnicka, I. and Lemański, G. (2016) 'Urban greenery as a component of real estate value', Real Estate Management and Valuation, 24(4), pp. 79-87. doi: 10.1515/remav-2016-0032.

Territoires, É. (2015) 'Fiche n`11 Le coefficient de biotope par surface (CBS)', Ecosystème dans les territoires - Cahiers techniques de l'AEU2 - Réussir la planification et l'aménagement durables, pp. 63-64. Available at: http://multimedia.ademe.fr/catalogues/CTecosystemes/index.html.

Thion, B. (1993) 'Valeur, prix et methodes d'evaluation en immobilier'.

Urbaine, E. and Po, S. (2015) 'Quartiers d' affaires : enjeux et prospective'.

Vischer, J. C. (2008) 'Towards an Environmental Psychology of Workspace: How People are Affected by Environments for Work', Architectural Science Review, 51(2), pp. 97-108. doi: 10.3763/asre.2008.5114.

Wilson, E. O. (1984) Biophilia. Harvard University Press. Available at: http://www.hup.harvard.edu/catalog.php?isbn=9780674074422\&content=reviews (Accessed: 7 June 2017). 